\title{
Zur Frage der Enzyme des Pankreas.
}

\author{
Von \\ Dr. Karl Mays.
}

(Der Redaktion zugegangen am 29. Januar 1907.)

Gegen die Kritik, die ich in dieser Zeitschrift, Bd. XLIX, S. $127 \mathrm{ff}$. an der Arbeit des Herrn H. M. Vernon im XXX. Bande des Journal of Physiology geübt habe, hat dieser (Bd. 50, S. 440 dieser Zeitschrift) einige Einwände erhoben, von denen ich jedoch nicht finden kann, daß sie meine Gründe gegen seine Auffassung von dem Vorkommen des Erepsins im Pankreas in irgend wie wesentlicher Weise berühren. Ich will diese Einwände der Reihe nach besprechen:

1. Gegen den ersten Einwand Vernons ist folgendes zu bemerken: Ich habe mich auf Vernons Angabe (S. 344) gestützt, daß der Anteil der Pankreasverdauung ungefähr hälftig dem Trypsin und dem Erepsin zufalle. Nun macht er zwar geltend, daß er verschiedentlich darauf hingewiesen habe, daß diese Berechnung nicht den Anspruch auf Genauigkeit machen könne; aber er stellt jetzt seine Angaben darüber als so wertlos hin, daß man nicht einsieht, warum er sich überhaupt der Mühe unterzogen hat, diese Berechnung anzustellen. Ich glaube aber nicht, daß Vernon dieselbe zur Zeit der Niederschrift seiner Arbeit so sehr unterschätzt hat, da er sie später wieder in Rechnung zieht, indem er S. 352 sagt, man müsse sich erinnern, daß ungefähr die Hälfte der anfănglichen peptonspaltenden Kraft dem Trypsin allein zufalle. Der Einwand hat aber überhaupt wenig Bedeutung, da, wenn man dem Trypsin im Sinne Vernons auch nur einige, irgendwie erhebliche Wirkung zuschreiben soll (nebenbei aber das Erepsin auch die gleiche Wirkung hat), es eben unverständlich bleibt, warum sich bei seinen Versuchen keine entsprechende Vermehrung der Spaltung der ersten Anteile des Peptons wenigstens nicht immer - durch das Trypsin gezeigt hat, da er doch eine Vermehrung dieses Enzyms auf nahezu das siebenfache durch seine fibrinlösende Kraft konstatiert hat (S. 343, am 22. Tage).

2. Was den Versuch Vernons mit dem Katzenpankreas betrifft, so unterschätze ich seine Bedeutung nicht; ich halte ihn für seinen besten Versuch, aber er steht, auch wenn er ganz einwandfrei wäre, zu vereinzelt da, um von voller Beweiskraft zu sein, und er hat seinen Wert nur vor Zusatz des Darmextraktes. Deshalb, meine ich, wäre es richtiger 
gewesen, den Versuch ohne diesen fortzusetzen oder zu wiederholen, und ich habe den Zusatz als unverständlich bezeichnet, weil ich nicht einsehe, was dadurch gewonnen ist. Er lehrt, daß in jenem Extrakte Zymogen vorhanden war. Es ist nun nicht ganz von der Hand zu weisen, daß vielleicht eine Vorstufe des Trypsins nicht lösend, wohl aber peptonspaltend wirke, aber das ist zunächst nicht anzunehmen und der Versuch von Bedeutung, sobald das Trypsin ausgeschlossen ist. Die Peptonspaltung hat der Zusatz von Darmextrakt mindestens kompliziert, und wenn Vernon doch einmal Zymogen hat konstatieren wollen, hätte er das besser in einem besonderen Versuche getan. Ich habe gesagt, daß man die Peptonspaltung in diesem Versuch auf Erepsin hätte beziehen können, aus verschiedenen Gründen: einmal, wie schon erwähnt, weil der Versuch zu vereinzelt ist, dann, weil ich aus meinen Versuchen ersehen hatte, daß geringe Mengen Trypsin der Beobachtung entgehen können und erst bei Zusatz gewisser Substanzen (in meinen Versuchen Pepton, dem man wohl keine kinetische, sondern nur eine lösungsunterstützende Wirkung zuschreiben kann) manifest werden. Wenn aber überhaupt Trypsin vorhanden ist, so darf man, wie ich gezeigt zu haben glaube, aus einer Verschiebung der lösenden und peptonspaltenden Wirkung noch nicht auf zwei Enzyme schließen. Ich muß hier noch bemerken, daß es mir nicht klar geworden ist, ob Vernon meint, daß in diesem Versuch vor dem Zusatz des Darmextraktes Trypsin ganz gefehlt hat. In der Tabelle findet sich in der Rubrik der tryptischen Wirkung ein Strich, der ebensogut das Fehlen des Trypsins bedeuten kann, als auch, daß er nicht darauf untersucht hat. Warum betont er diese Abwesenheit nicht im Text und warum sagt er auch jetzt wieder, daß die fibrinlösende Kraft beinahe ganz und gar abwesend war? Vernon wirft mir vor, daß man aus meiner Arbeit den Eindruck gewinne, als ob er den Darmauszug zugesetzt hätte, ehe er den Pankreasauszug auf Erepsin untersucht hätte (also auch hier keine Erwăhnung, daß er damals auf Trypsin untersucht hätte). Im Text seiner Abhandlung sagt V ernon, daß dieses Pankreasextrakt im Anfang epracticallys kein freies Trypsin enthalten hătte, welches Wort dessen Anwesenheit nicht ganz ausschließt. Es scheint mir noch jetzt nicht ganz klar, ob dieser Satz sich auf den Versuch vor oder nach dem Zusatze des Darmextraktes bezieht; ich habe ihn auf den ersteren Fall beziehen zu müssen geglaubt, und in diesem Sinne habe ich gesagt, daß sein Extrakt im Anfang, also vor dem Zusatz des Darmextraktes, kaum fibrinlösend wirkte.

3. Bezüglich der Trennung der Enzyme durch Alkohol gebe ich $\mathrm{zu}$, daß ich Vernons Angaben nicht so verstanden habe, wie er sie jetzt erklärt. Genau gibt er zwar auch jetzt noch nicht an, wie er diese Versuche gemacht hat, wenn er auf frühere Vorschriften hinweist, wo von $1 \mathrm{ccm}$ resp. $0,3 \mathrm{ccm}$ oder weniger die Rede ist. Wenn ich aber schon dort nicht verstehe, warum er seine Extrakte so sehr verdünnt 
hat, viel weniger hier, wo seine Alkoholniederschläge nach ihm selbst doch nur Teile des oder der Enzyme enthielten, und gar nicht, wo seine Filtrate durch den Alkohol sehr verdünnt waren. Einerlei, wie or seine Versuche angestellt hat, so beziehen sich seine Einwände auch hier nur auf nebensächliche Dinge und treffen nicht das Wesentliche meiner Kritik.

Bei den Fragen über die Natur der Enzyme steht die mit im Vordergrunde, wieviel man deren anzunehmen berechtigt ist, worüber zur Zeit lebhaft diskutiert wird. Wegen ihrer Wichtigkeit sollte man sich aber sehr vor nicht ganz schlagenden Tatsachen und Beweisführungen hüten, und wenn es auch, wie z. B. Referate lehren, keine dankbare Aufgabe ist, so, meine ich, tue man der Wissenschaft einen größeren Dienst, wenn man hier etwas zurückhaltend ist, wenn man dabei auch der Befriedigung, die schöne Resultate gewähren, verlustig geht. Ich glaube mich zu dieser Warnung um so mehr berechtigt, als ich selbst die Idee des Vorkommens des Erepsins im Pankreas zuerst ausgesprochen habe. 